\title{
Transition Metal Ordering Optimization for High-Reversible Capacity \\ Positive Electrode Materials in the Li-Ni-Co-Mn Pseudoquaternary \\ System
}

R. C. Longo ${ }^{1}$, F. Kong ${ }^{1}$, C. Liang ${ }^{1}$, D. -H. Yeon², J. Yoon², J. -H. Park², S. -G. Doo², and

K. Cho ${ }^{1}$

${ }^{1}$ Department of Materials Science \& Engineering, The University of Texas at Dallas,

Richardson, Texas 75080, USA

${ }^{2}$ Energy Lab., Samsung Advanced Institute of Technology, Samsung Electronics, Yongin

446-712, Republic of Korea

Table S1. Total energies (in eV) of the $\mathrm{LiNi}_{1-\mathrm{y}-\mathrm{x}} \mathrm{Co}_{\mathrm{y}} \mathrm{Mn}_{\mathrm{x}} \mathrm{O}_{2}$ stoichiometries studied in this work. Only the Ni, Co and Mn total compositions are shown.

\begin{tabular}{|l|l|l|l|l|l|}
\hline Structure & Energy & Structure & Energy & Structure & Energy \\
\hline $16,16,16$ & -1083.08994071 & $18,18,12$ & -1058.52333906 & $20,20,8$ & -1032.44194103 \\
\hline $22,22,4$ & -1009.03432329 & $24,24,0$ & -985.83844597 & $20,14,14$ & -1064.81526175 \\
\hline $24,12,12$ & -1046.67351406 & $28,10,10$ & -1029.87239464 & $32,8,8$ & -1012.19807639 \\
\hline $36,6,6$ & -994.60357648 & $40,4,4$ & -977.46455101 & $44,2,2$ & -959.90111443 \\
\hline $48,0,0$ & -942.37476003 & $14,20,14$ & -1076.33349110 & $12,24,12$ & -1069.56794718 \\
\hline $10,28,10$ & -1063.31765735 & $8,32,8$ & -1057.04224443 & $6,36,6$ & -1050.64606312 \\
\hline $4,40,4$ & -1044.45302168 & $2,44,2$ & -1038.58690522 & $0,48,0$ & -1031.98691061 \\
\hline $18,12,18$ & -1088.79696761 & $20,8,20$ & -1094.34433774 & $22,4,22$ & -1099.68050304 \\
\hline $24,0,24$ & -1090.84510543 & $12,18,12$ & -1097.03179244 & $8,20,20$ & -1111.05009729 \\
\hline $4,22,22$ & -1124.31091153 & & $0,24,24$ & $14,14,20$ & -1102.60244352 \\
\hline $12,12,24$ & -1122.32893624 & $10,10,28$ & -1141.64332648 & $8,8,32$ & -1160.13853298 \\
\hline $6,6,36$ & -1178.72253938 & $4,4,40$ & -1196.78949660 & $2,2,44$ & -1214.82961681 \\
\hline $0,0,48$ & -1232.40047492 & & & & \\
\hline
\end{tabular}


Figure S1. PDOS of the Ni, Co and Mn TM of the NCM111 superstructures studied in this work, with their corresponding Traces.

a) Trace 0

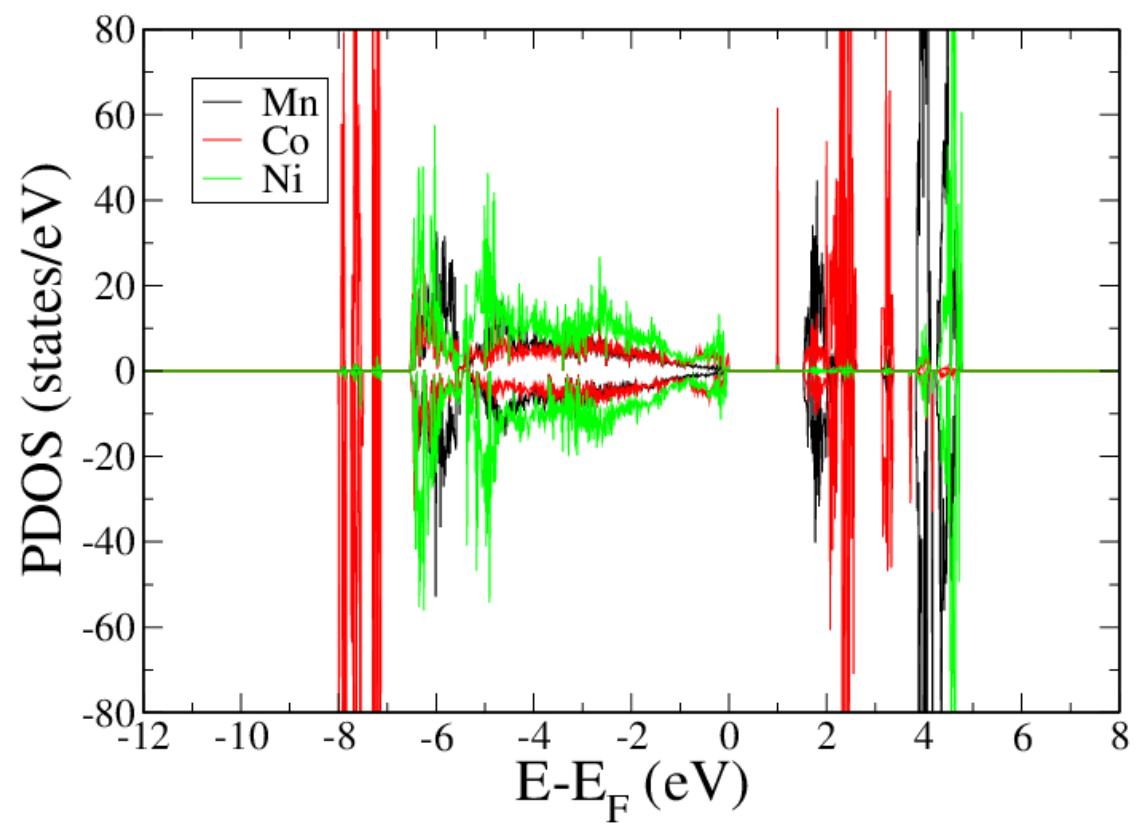

b) Trace 4

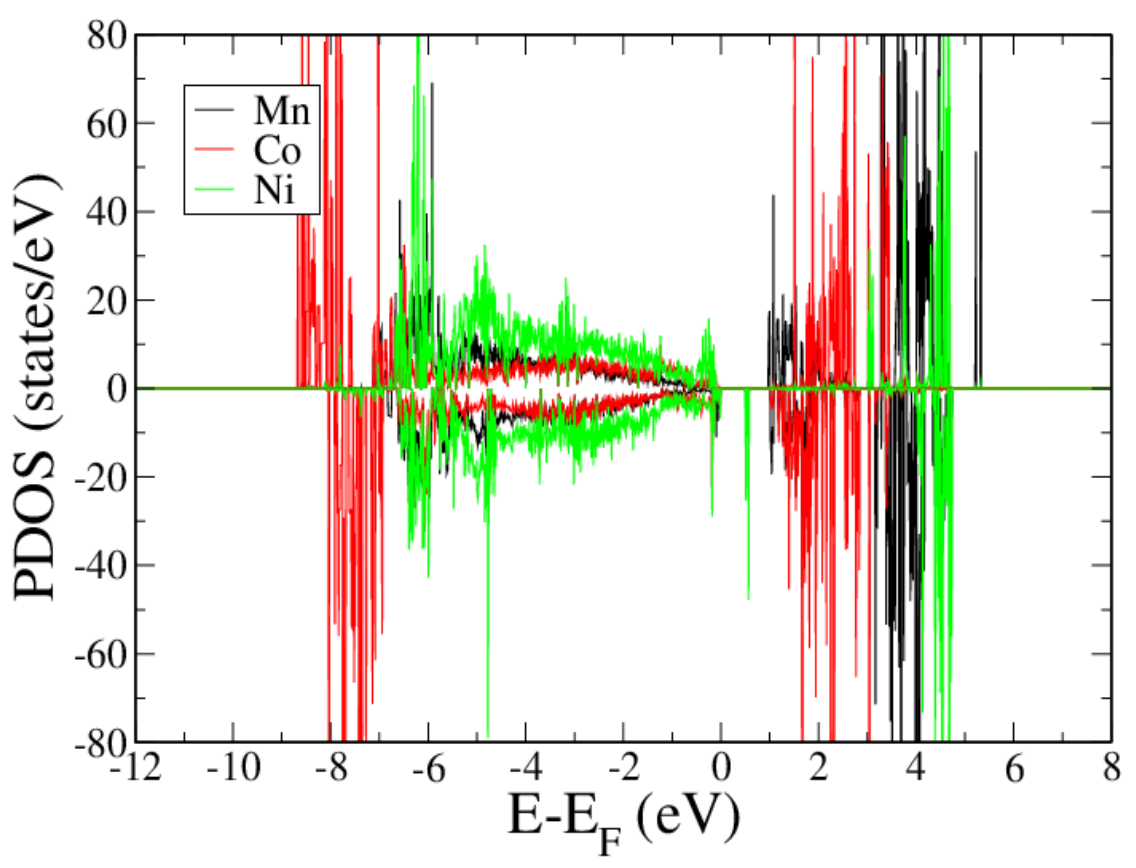


c) Trace 6

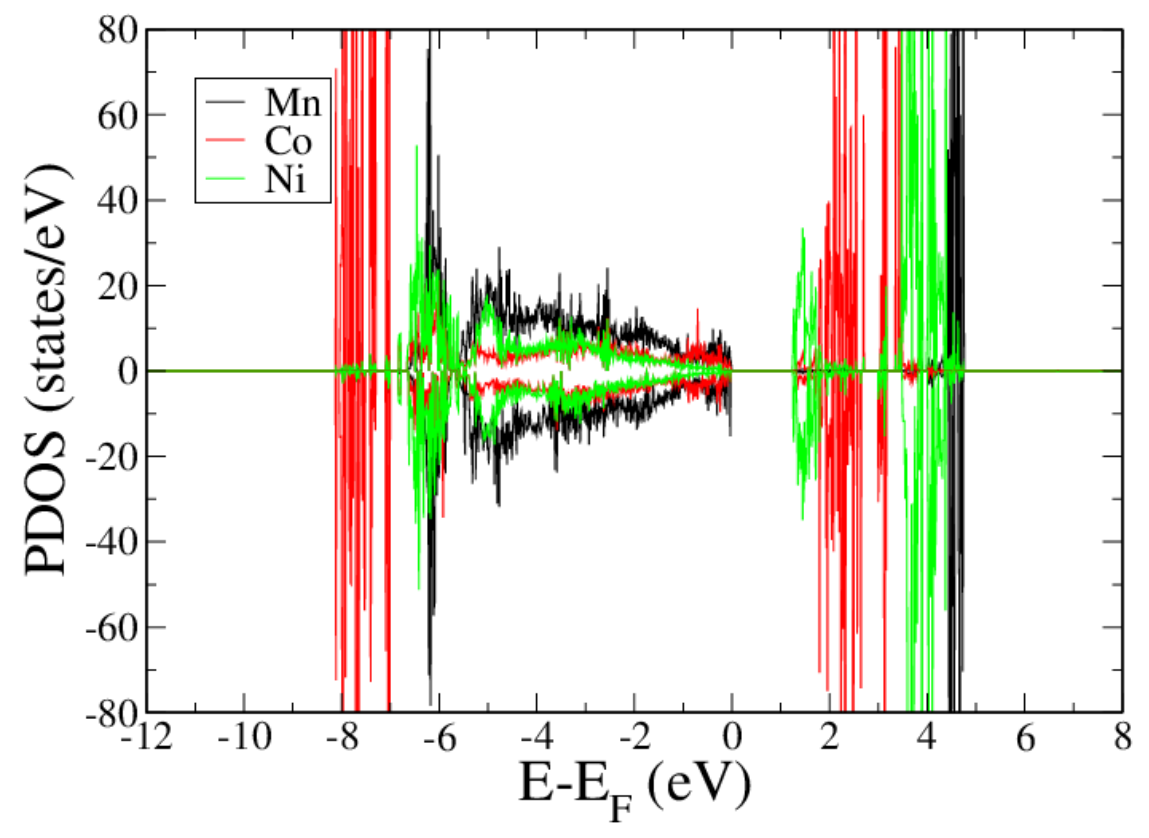

d) Trace 10

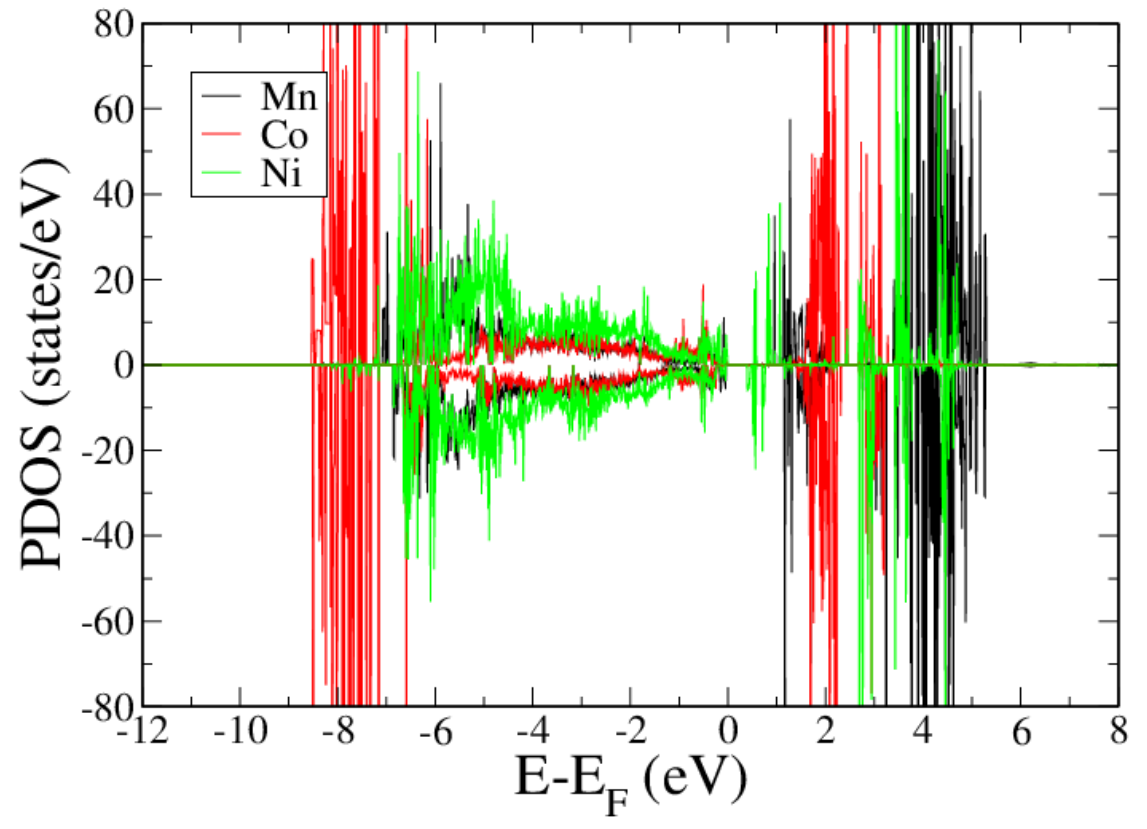


e) Trace 18

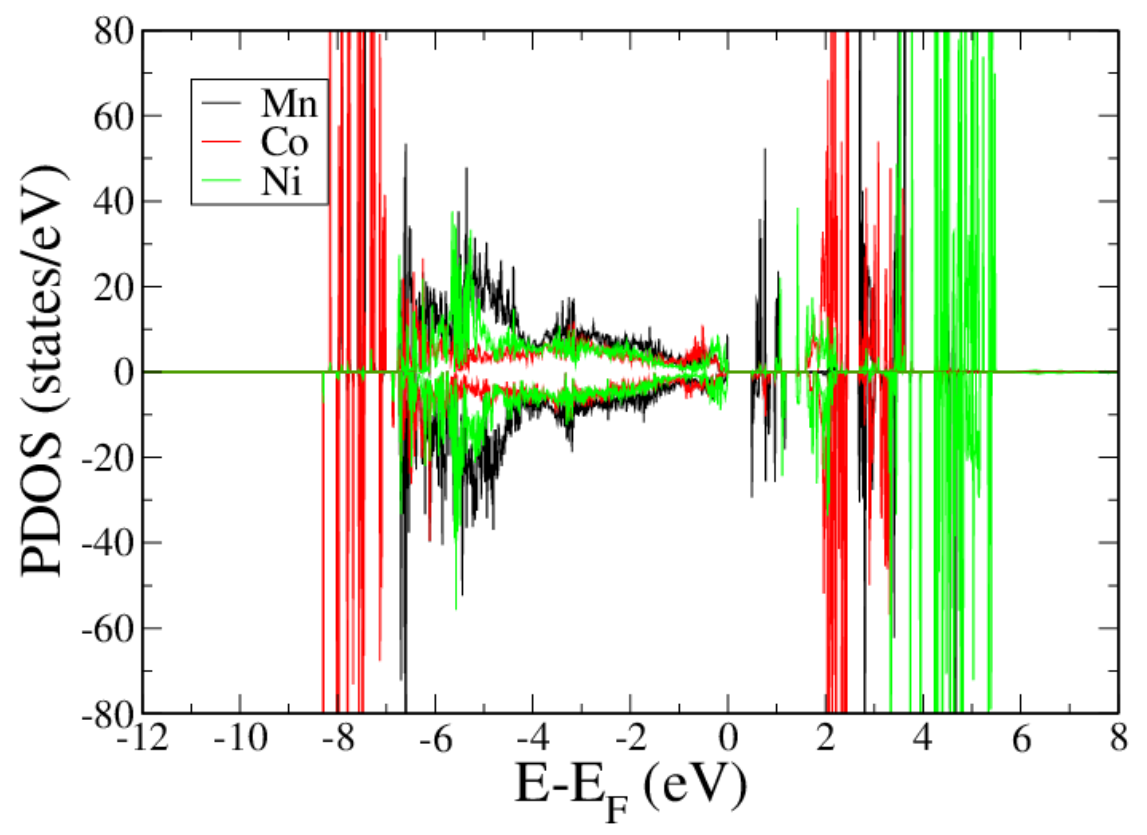

Table S2. Kinetic diffusion barriers for single layered oxides (marked in red) and with $\mathrm{TM}$ substitution at the transition state (in $\mathrm{eV}$ ).

\begin{tabular}{|l|l|l|l|}
\hline & $\mathrm{LiNiO}_{2}$ & $\mathrm{LiCoO}_{2}$ & $\mathrm{LiMnO}_{2}$ \\
\hline $\mathrm{Ni}$ & 0.41 & 0.36 & 0.50 \\
\hline $\mathrm{Co}$ & 0.36 & 0.31 & 0.38 \\
\hline $\mathrm{Mn}$ & 0.61 & 0.56 & 0.60 \\
\hline
\end{tabular}

